\title{
DO CENTRO-OESTE BRASILEIRO AO NORTE PORTUGUÊS: EXPERIÊNCIA(S) COM A TERAPIA COMUNITÁRIA INTEGRATIVA
}

\author{
DESDE EL CENTRO-OESTE DE BRASIL AL NORTE DE PORTUGUÉS: \\ EXPERIENCIA (S) CON TERAPIA COMUNITARIA INTEGRATIVA
}
FROM CENTRAL-WESTERN BRAZIL TO NORTHERN PORTUGUESE: EXPERIENCE(S) WITH INTEGRATIVE COMMUNITY THERAPY

Lucas Rodrigo Batista LEITE ${ }^{1}$

Cássia Maria Carraco PALOS ${ }^{2}$

RESUMO: Busca-se nesse texto descrever as principais ações com a Terapia Comunitária Integrativa, de 2017 a 2019, desde Cuiabá - MT, no centro-oeste brasileiro, até a cidade de Bragança, no norte português, apontando para a diversidade de grupos atendidos, bem como para a cultura e a faixa etária como elementos a serem considerados, para a efetividade da roda de terapia. Ademais, esse trabalho objetiva contribuir com a divulgação da TCI, apontando para possiblidades futuras de pesquisa ou servindo como fundo/base/dado, para a mesma.

PALAVRAS-CHAVE: Terapia comunitária integrativa. Experiência. Brasil. Portugal. Extensão universitária.

RESUMEN: Este texto busca describir las principales acciones con Terapia Comunitaria Integrativa (TCI), de 2017 a 2019, desde Cuiabá - MT, en el centro-oeste de Brasil, hasta la ciudad de Bragança, en el norte de Portugal, señalando la diversidad de grupos atendidos, así en cuanto a la cultura y el grupo de edad como elementos a considerar, para la efectividad de la rueda terapéutica. Además, este trabajo tiene como objetivo contribuir a la difusión de las TCI, apuntando a futuras posibilidades de investigación o sirviendo como fondo / base / datos para la misma.

PALABRAS CLAVE: Terapia comunitaria integrativa. Experiencia. Brasil. Portugal. Extensión universitaria.

ABSTRACT: This text seeks to describe the main actions with Integrative Community Therapy (TCI), from 2017 to 2019, from Cuiabá-MT, in central-western Brazil, to the city of Bragança, in northern Portugal, pointing out the diversity of groups served, as well as the culture and age group as elements to be considered for the effectiveness of the therapy circle. Furthermore, this

${ }^{1}$ Universidade Federal de Mato Grosso (UFMT), Cuiabá - MT - Brasil. Mestrando em Saúde. Vice-coordenador do Programa de Extensão ConstruISC e coordenador da Ação de Extensão SaDiL (Saúde, Discurso e Linguagem). ORCID: https://orcid.org/0000-0001-5265-8742.E-mail: batistaleitelucas@gmail.com

${ }^{2}$ Universidade Federal de Mato Grosso (UFMT), Cuiabá - MT - Brasil. Professora Adjunta do Instituto de Saúde Coletiva. Doutorado em Saúde Pública (USP). ORCID: https://orcid.org/0000-0003-3514-0436. E-mail: cacapalos@gmail.com 
work aims to contribute to the dissemination of the TCI, pointing to future possibilities of research or serving as background/data to it.

KEYWORDS: Integrative community therapy. Experience. Brazil. Portugal. University extension.

\section{Introdução}

Há algum tempo vimos sistematizando nossas práticas com a/na Terapia Comunitária Integrativa (TCI): Projeto Laços (2019) ${ }^{3}$, TCI no norte de Portugal (2019) ${ }^{4}$, Projeto Aconchega $(2019 ; 2018 ; 2017)^{5}$, Vivência em TCI $(2019)^{6}$, TCI no VER-SUS $(2018)^{7}$, TCI com idosos em Portugal $(2018)^{8}$. Com a intenção de deixar rastros/vestígios dessa prática integrativa e complementar em saúde e as suas possibilidades de inserção em diferentes contextos e grupos.

A Terapia Comunitária é um recurso terapêutico de grupo, criada pelo médico brasileiro Adalberto Barreto, na periferia de Fortaleza - CE, que se constitui como um espaço sociocultural de vivência e convivência, onde as pessoas ouvir, falar e compartilhar seus problemas, produtores de sofrimento no cotidiano (BARRETO; LAZARTE, 2013).

Nossa aproximação com a TCI, deu-se por intermédio da extensão universitária, que se configura como a devolutiva da universidade para a sociedade, para as comunidades; ou dito de outra forma, é o trabalho com a comunidade, no intuito de superar (ou iniciar a superação) de suas principais necessidades. Em 2016, durante uma coleta de demandas para intervenção, por meio de um projeto de extensão em desenvolvimento na periferia de Cuiabá - MT, consideramos a potencialidade da Terapia Comunitária no manejo das questões; à medida que íamos anotando as problemáticas, lembrávamos do projeto de TCI, executado pelo Programa de Educação Tutorial (PET) Conexões de Saberes da UFMT. O PET Conexões de Saberes é um projeto que tem como objetivo agregar estudantes de origem popular, de forma interdisciplinar, estimulando o protagonismo destes na organização e desenvolvimento de ações, com as quais se identifiquem, a serem implementadas, precipuamente, em comunidades populares/periferias (BATISTA LEITE et al., 2019). Entretanto, justamente por também sermos membros do PET e acompanharmos a atuação do projeto, sabíamos que o mesmo não

${ }^{3}$ Artigo/relato de experiência publicado em revista portuguesa (AdolesCiêcia - IPB).

${ }^{4}$ Trabalho apresentado no Congresso da ABRATECOM, em Salvador - BA.

5 Trabalhos apresentado: em 2017, no Encontro Estadual de Saúde Coletiva (ISC/UFMT); em 2018, na Jornada Internacional Científica (IPB - Portugal) e no Congresso da ASPESM (Portugal, que rendeu publicação em ebook) e; em 2019, no Fórum Mato-grossense de Promoção da Saúde (Mato Grosso).

${ }^{6}$ No Encontro dos Grupos PET do Centro - Oeste/ECOPET (Cuiabá).

${ }^{7}$ Trabalhos apresentado no Congresso Internacional da Rede Unida (Manaus).

${ }^{8}$ Trabalho apresentado na Jornada Internacional Científica (IPB - Portugal). 
poderia assumir essa incumbência, uma vez que já possuía uma demanda expressiva de ações a serem executadas. Foi então que nos colocamos a disposição para o processo de formação em TCI.

Em Mato Grosso, a primeira formação de terapia comunitária ocorreu em 2008/2009, na cidade de Sorriso, sendo promovida pela Secretaria de Estado de Saúde, em parceria com o Ministério da Saúde e os polos de formação em TCI, credenciados pela Associação Brasileira de Terapia Comunitária (ABRATECOM). Nessa turma, estavam presentes as professoras Rosa Lúcia R. Ribeiro (Faculdade de Enfermagem/UFMT) e Mirian Sewo (Instituto de Educação/UFMT) que, após o curso de imersão, começaram a realizar rodas de TCI na cidade de Cuiabá, em unidades hospitalares, na própria universidade e na periferia do município (PET CONEXÕES) (UFMT, 2020). Inseridas na Pró-reitoria de Assistência Estudantil/UFMT (PRAE), que como o próprio nome sugere, visa assistir os estudantes, atendendo as principais demandas socioassistenciais e assegurando a permanência desses alunos na instituição (UFMT, 2020), articularam em 2013/2014, uma nova formação em TCI; dessa vez, na cidade de Cuiabá (RIBEIRO, 2020). Nossa participação deu-se na terceira formação, implementada em 2016, no município de Sinop e que também foi um projeto da PRAE, articulado juntamente com Supervisão de Assistência Estudantil da UFMT/Sinop, que coordenou o projeto.

A partir da nossa inserção na TCI, saímos com o compromisso/a responsabilidade de disseminar e implementar esse recurso terapêutico de grupo, nos nossos respectivos lugares de labor. Como nosso contexto de trabalho tem sido a universidade, especialmente seu pilar "extensão", é aí que temos exercido, prioritariamente, a terapia comunitária. Logo, esse texto tem a intenção de "juntar", no relato de experiência, esse nosso breve percurso com a/na TCI.

\section{No centro-oeste brasileiro, o Aconchega}

Findado o processo formativo em Sinop, um grupo de egressos, da/na cidade de Cuiabá, especificamente, da Universidade Federal de Mato Grosso, juntamente com terapeutas comunitários já formados e atuantes no município, se reuniram para propor um projeto, como contrapartida à universidade, que custeou o processo formativo. No município já existia um projeto consolidado de TCI, em funcionamento na Unidade de Referência de Práticas Integrativas e Complementares em Saúde da Secretaria Municipal de Saúde, desde 2013 (RIBEIRO, 2020) - que inclusive fora iniciado pelo PET. Mas o que se propunha ali, era um espaço dedicado ao ambiente universitário, dada a alta demanda por apoio psicossocial, 
recebidos pela PRAE, e o número expressivo de casos de suicídio entre estudantes da universidade.

Entre as primeiras pautas do grupo estava a escolha do nome do projeto. Uma das sugestões foi Escutatória, uma aglutinação que aludia para a importância da escuta e da(s) história(s) nas rodas de TCI. Mas ao final, após um debate caloroso, o escolhido foi Aconchega, por sugestão de um dos terapeutas participantes, emergindo como nome e síntese do projeto um espaço de aconchego. Segundo Bartniski e Carvalho "O nome do projeto não é [...] acaso, aconchega é uma palavra que aproxima, que conforta, que faz com que os participantes se sintam acolhidos, aconchegados" (BARTNISKI; CARVALHO, 2019, p. 3). E esse nome veio ao lembrar dos estudantes que saem do aconchego de seus lares, familiares, amigos, em busca de um sonho (o curso superior) e que nesse processo, muitas vezes, sofrem com a distância, com a falta. O Aconchega veio para ajudar a lidar com essa questão.

Enquanto projeto de extensão, o Aconchega, iniciado em maio de 2017 e com rodas semanalmente, se constituiu como um espaço de acolhimento e cuidado em saúde mental à comunidade acadêmica, bem como a comunidade externa (BATISTA LEITE et al., 2018), onde esses podiam compartilhar suas vivências/experiências, sejam de alegria ou tristeza; um espaço de promoção da interação e construção de redes de solidariedade (BARTNISKI; CARVALHO, 2019).

De 2017 a 2019, o Projeto Aconchega atendeu 621 pessoas, em 75 rodas de TCI, como mostra o quadro 1.

Quadro 1 - Número de rodas e participantes do Projeto Aconchega UFMT, 2017 a 2019

\begin{tabular}{|c|c|c|}
\hline Ano & $\mathbf{N}^{\mathbf{0}}$ rodas & $\mathbf{N}^{\mathbf{0}}$ participantes \\
\hline 2017 & 26 & 176 \\
\hline 2018 & 24 & 133 \\
\hline 2019 & 25 & 312 \\
\hline Total & 75 & 621 \\
\hline
\end{tabular}

Fonte: Projeto Aconchega (UFMT)

\section{A TCI no Norte Português}

Como dissemos outrora (BATISTA LEITE et al., 2019), logo que chegamos em Bragança, Portugal, para a realização de nossa mobilidade internacional, nos integramos a Associação de Estudantes Brasileiros (AEBIBP), já que nosso percurso no Brasil, era marcado por processos de participação em variadas instâncias acadêmicas, desde a representação 
estudantil até projetos de ensino, pesquisa e extensão, sobretudo, nesse último. Na associação, fora solicitado, pela direção, à comunidade estudantil, a oferta de atividades a própria comunidade. De nossa parte, dada a nossa formação, propomos a oferta de rodas de TCI e aplicação de Reiki; mas como esta última prática demandava mais tempo e atendia menos pessoas - não que fosse menos importante - decidimos pela realização apenas da TCI.

No momento de nossa entrada na associação, estava em trâmite um processo de cooperação entre ela e uma associação local de artesãos. Dessa forma, nossa proposta de atividade entrou como objeto principal na cooperação, que firmou a realização semanal de rodas de terapia com usuários da instituição. Demos então a essa ação o nome de Roda Terapêutica, que se configurou como um projeto.

No período de abril a junho de 2018, o Projeto Roda Terapêutica realizou 7 rodas, atendendo 78 participantes, em sua maioria, idosos. Dentre os problemas mais recorrentes nas rodas, estavam a falta de paz, preocupação, impotência, tristeza, ansiedade e medo. Após as sessões, os sentimentos levados eram de amor, fraternidade, força, amizade, paz, aprendizagem, afeto, coragem e paciência.

A fim de identificarmos mais precisamente os benefícios antes e após a roda de TCI, bem como identificar o que poderia ser modificado ou continuado no projeto, elaboramos um instrumento de avaliação (figura 1), que cada participante preenchia no final da roda. $\mathrm{O}$ instrumento continha três fichas, com a mesma numeração, no intuito saber que as respostas se tratava da mesma pessoa, e em cores diferentes, para facilitar aos idosos, que porventura apresentassem dificuldade de leitura.

Figura 1 - instrumento avaliativo das rodas de TCI

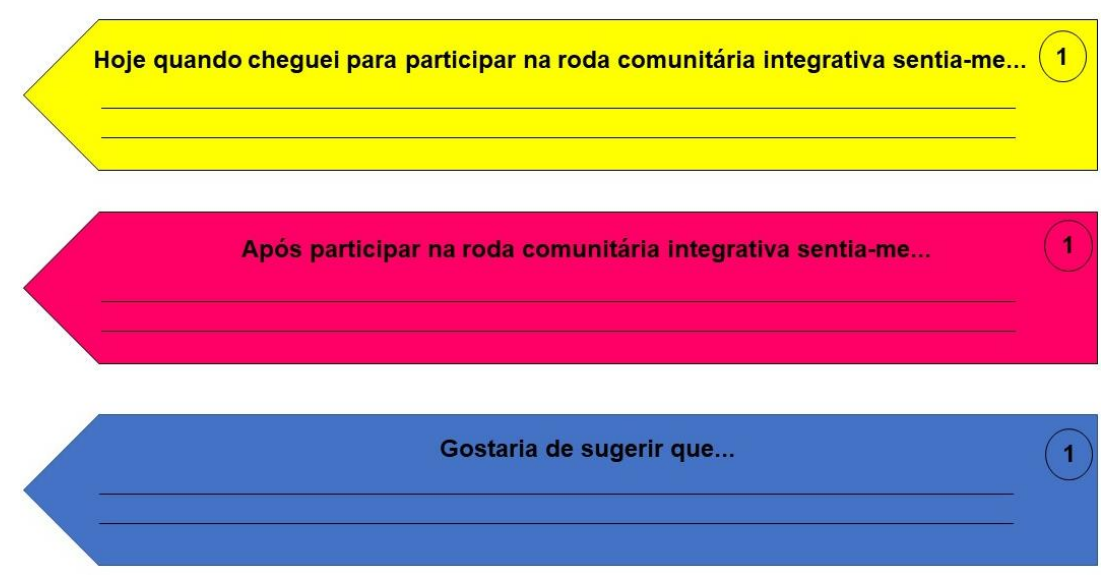

Fonte: elaborado por Lucas Leite, com revisão de Jéssica Botelho (2018) 
Das respostas, destacamos uma que nos marcou. Marcou, pois, tratava-se de um caso recorrente nas rodas. Uma senhora, assídua em nossas atividades, sempre apresentava o mesmo problema: a sobrinha em situação de drogadição. E, sendo ela sua única família, pedia-nos que intervíssemos. Nossa resposta era sempre a mesma: traga ela a nossa roda, é o que podemos oferecer. E ela o fez. Na última TCI que realizamos na associação, ela conseguiu levar a sobrinha, que permaneceu durante toda a roda em silêncio, observando, respondendo apenas no final, nas conotações positivas (o que se está levando da roda): "que a terapia não é um lugar de covardes". Ainda pudemos ler em sua avaliação:

Quando chegou, sentia-se: Ainda pouco em mim pelas crises que me deram nos últimos dias;

Após a TCI, sentia-se: Com uma porta a abrir;

Sugestão: Não fiquem com a imagem que tiveram de mim hoje, para outra altura.

Infelizmente o projeto não teve continuidade, por questões burocráticas, mas conseguimos vislumbrar a potencialidade da terapia comunitária com esse grupo específico.

Ainda nesse semestre, organizamos junto a AEBIPB, uma Jornada Internacional Científica, onde propomos a realização de uma roda de Terapia Comunitária, como atividade minicurso, do evento. A roda contou como 9 participantes, sendo todos estudantes brasileiros e teve como tema escolhido "angústia com o futuro". Entre as estratégias de enfrentamentos apontadas estavam: mudar de cidade e profissão, apoio dos amigos, viver um dia de cada vez/o agora e cobrar-se menos. Os participantes levaram da roda partilha, gratidão, acolhimento etc. Essa, sem dúvidas, foi a roda mais emotiva que fizemos em solo português.

O acúmulo propiciado pelo projeto Roda Terapêutica e pelo minicurso, que em verdade, foi uma vivência, permitiu-nos criar o Projeto Laços, que objetivava a realização de TCI com estudantes (BATISTA LEITE et al., 2019). Foram realizadas 11 sessões com a participação de 40 estudantes, cujas atividades não cabem aqui explicitá-las uma vez que se encontram publicadas no periódico AdolesCiência, do IPB.

Nossas últimas ações em terras lusitanas, em relação a terapia comunitária, se resumem a duas rodas, que em verdade, diríamos não ser uma terapia comunitária em si, mas espaços de escuta e fala, utilizando os elementos metodológicos da TCI. Trata-se de uma roda, realizada em um sarau universitário, a convite de um estabelecimento comercial bragantino; e outra, desenvolvida dentro de um projeto de intervenção em andamento, na Santa Casa de Bragança.

Podemos dizer que nossas ações, de certa forma, marcam a história da TCI em Portugal, já que como pode ser consultado na página da Associação Europeia de Terapia Comunitária 
Integrativa $^{9}$, a prática teve início no país, em setembro de 2018, na cidade de Sintra e que atualmente vem sendo impulsionada pela Associação Movimento Integrado de Saúde Ambiental e Comunitária - AMISAC.

\section{De volta ao centro brasileiro}

Logo que regressamos ao Brasil, em fevereiro de 2019, nos incluímos novamente nas atividades de terapia comunitária, junto ao Aconchega e em ações paralelas. Entre essas ações, apontamos uma oficina-vivência que realizamos no Encontro Regional dos Programas de Educação Tutorial do Centro - Oeste (ECOPET) e nossa participação, pela primeira vez, no Congresso da ABRATECOM, em setembro/2019.

Em vias de fechamento, gostaríamos de retomar uma ação marcante: ao final de 2019, o Aconchega, a convite de uma escola pública de Cuiabá, realizou rodas de TCI, com professores e estudantes, durante dois dias, sendo que um deles foi utilizado inteiramente para atendimento dos alunos. Ao todo foram realizadas 04 rodas - 01 com professores (20 participantes) e 03 com estudantes (98 participantes) do ensino fundamental e médio. O que nos chamou atenção nessas rodas foi o desgaste emocional, de toda a comunidade escolar atendida.

Entre os professores, prevaleceu a angústia/frustração com a falta de valorização da categoria e a falta de estrutura para o exercício da docência; sentimento esse, unanime entre os participantes que, transformaram a roda, em alguns momentos, em lócus de desabafo coletivo. Já em relação aos alunos, destacamos uma roda, na qual duas questões sobressaíram-se: o sofrimento de um estudante transsexual, em fase de transição e a autossentença de morte dada por outro, em virtude de marca estética.

A roda em questão estava programada para seguir o protocolo habitual, utilizado na maioria das terapias, nas quais o tema a ser aprofundado emerge na própria roda, mas ocorreu que os estudantes não queriam participar de nenhuma forma. Decidimos então modificar o protocolo, propondo uma roda temática e tomando como mote o seguinte: quem aqui já passou por uma situação de bullying ou preconceito e como fez para lidar/superar? Foi aí que os alunos começaram a tomar a fala. 06 estudantes relaram suas histórias. Entre eles, um aluno em fase de transição sexual, que relatou a falta de apoio familiar e que a escola era seu único refúgio e que, mesmo assim, as vezes sofria nesse espaço, com o preconceito de pessoas que não o

${ }^{9}$ Disponível em: https://www.aetci-a4v.eu/europe/portugues/. Acesso em 07 fev. 2020.

Temas em Educ. e Saúde, Araraquara, v. 16, n. esp. 1, p. 286-295, set., $2020 . \quad$ e-ISSN 2526-3471. 
compreendiam. E um outro, de quatorze anos, que tinha se dado um tempo de vida (até os 20 anos), caso não conseguisse realizar um tratamento odontológico para corrigir um desvio odontológico, que o fazia parecer "banguela ${ }^{10 "}$ e, consequentemente, ser vítima de bullying constante. Importa dizer que esse aluno, durante a roda, esteve a maior parte do tempo com fone no ouvido, com som extremamente alto e só "entrou na roda", a partir do depoimento emotivo do estudante trans. O comovente ali fora os demais alunos chorando e, no final, se abraçando, pedindo desculpas, apoiando-se uns aos outros.

Não menos importante, vale dizer que o Aconchega ganhou, em novembro de 2019, menção honrosa como experiência exitosa em promoção da saúde, pela Secretaria de Estado de Saúde de Mato Grosso.

\section{Considerações finais}

Se nesse breve percurso de três anos com a TCI pudemos vivenciar os distintos sofrimentos humanos, nos diferentes grupos e em distintas culturas, também conseguimos comprovar aquilo que aprendemos com Adalberto Barreto: "quem tem o problema, tem a solução".

De nossa experiência em dois países distintos, destacamos a importância da cultura, de compreender as pessoas a partir de seus locais de origem, na compreensão dos sentimentos/problemas/necessidades, bem como na busca coletiva de soluções. Se não considerada, a cultura pode vir a se tornar uma limitação para a efetividade da roda de terapia.

Considerar a faixa etária também é fator primordial. Se por um lado, os idosos, muitas vezes querem falar em excesso ou se colocam no direito de aconselhar, dada suas experiências de vida (independente das regras da roda), por outro, os adolescentes se fecham, se calam, exigindo do terapeuta habilidades de adaptação e/ou inovação compatíveis com esse público.

A TCI com seu método simples, tem se constituído como um potente recurso de cuidado e promoção em saúde metal e esse trabalho tem o único e exclusivo objetivo de contribuir com a sua divulgação, apontando para possiblidades futuras de pesquisa ou servindo como fundo/base/dado, para a mesma.

Parafraseando Mariani (2018, p. 44), que relata um conselho que recebeu de sua orientadora, a linguista Eni Orlandi: "aprenda a proteger o seu trabalho, trabalhando. O trabalho, quando é bom, aparece por si só”. Diríamos que esse é o caminho que temos feito com

${ }^{10}$ Pessoa sem dente(s). 
a TCI: protegendo-a, realizando rodas; deixando livre a quem quiser ver/vivenciar, seus benefícios e repercussões.

AGRADECIMENTOS: gostaríamos de registrar aqui nossos agradecimentos: a Jéssica Botelho Pinto (brasileira, filha de português, que trabalhava na associação de artesãos), a Matheus Pereira Dias e Gabriela Sousa (estudantes brasileiros em mobilidade, em Bragança), por toda parceria e colaboração na organização do Projeto Roda Terapêutica. Agradecemos principalmente a Jéssica, que convidava os participantes e fazia o papel de "tradutora", quando havia dificuldades de entendimento/interpretação, na roda.

\section{REFERÊNCIAS}

BARRETO, A. P.; LAZARTE, R. Uma Introdução à Terapia Comunitária Integrativa: Conceito, bases teóricas e método. In: FERREIRA FILHA, M. O.; LAZARTE, R.; DIAS, M. D. Terapia comunitária integrativa: uma construção coletiva do conhecimento. João Pessoa: Editora Universitária da UFPB, 2013.

BATISTA LEITE, L. R. et al. Cuidado de promoção à saúde mental na universidade: Experiência com a Terapia Comunitária Integrativa. In: SEQUEIRA, C. et al. (Eds.). Congresso Internacional ASPESM, 9., 2018, Porto. Anais [...]. Porto, Portugal: ASPESM, 2018 .

BATISTA LEITE, L. R. et al. PET - Universidade, Saúde e Cidadania. In: BRITO, D. A. PET: 40 anos de ensino, pesquisa e extensão. 1. ed. Porto Alegre: PLUS/Simplíssimo, 2019.

BATISTA LEITE, L. R. et al. Projeto laços: promoção de saúde mental com a Terapia Comunitária Integrativa - Relato de Experiência. adolesCiência, [S.1.], v. 6, n. 1, p. 96-103, dez. 2019. ISSN 2182-6277. Disponível em:

https://www.adolesciencia.ipb.pt/index.php/adolesciencia/article/view/271. Acesso em: 08 fev. 2020.

BARTNISKI, J.; CARVALHO, H. Projeto aconchega: prevenção do adoecimento mental na UFMT. In: Congresso de Ciências da Comunicação na Região Centro-Oeste, 21., 2019, Goiânia. Anais [...]. Goiânia, maio, 2019. Disponível em http://portalintercom.org.br/anais/centrooeste2019/resumos/R66-0028-1.pdf. Acesso em: 08 fev. 2020.

MARIANI, B. Ao discurso, que nos uniu. Para Eni Orlandi. Traços de Linguagem, Cáceres, v. 2, n. 1, p. 36-49, 2018.

RIBEIRO, R. L. R. Terapia Comunitária Integrativa. Disponível em: https://sites.google.com/site/petconexoesdesaberesufmt/terapia-comunitaria. Acesso em: 08 fev. 2020. 
UFMT. Universidade Federal de Mato Grosso. Pró-reitoria de Assistência Estudantil.

Disponível em: https://www1.ufmt.br/ufmt/un/prae. Acesso em: 08 fev. 2020.

\section{Como referenciar este artigo}

LEITE, L. R. B.; PALOS, C. M. C. Do centro-oeste brasileiro ao norte português: experiência(s) com a terapia comunitária integrativa. Temas em Educ. e Saúde, Araraquara, v. 16, n. esp. 1, p. 286-295, set., 2020. e-ISSN 2526-3471. DOI: https://doi.org/10.26673/tes.v16iesp.1.14308

Submetido em: 20/05/2020

Revisões requeridas: $30 / 05 / 2020$

Aprovado em: 25/08/2020

Publicado em: 30/09/2020 